\title{
The Collaboration of Health Workers in Providing Integrated Antenatal Care at Oepoi Health Center, in East Nusa Tenggara, Indonesia
}

\author{
Jeffrey Jap ${ }^{1}$, Stefanus Supriyanto ${ }^{2}$, Nyoman Anita Damayanti ${ }^{3}$ \\ ${ }^{1}$ Doctoral Student, Program of Public Health, ${ }^{2}$ Professor, Department of Health Administration and \\ Policy, ${ }^{3}$ Lecturer, Department of Health Administration and Policy, Faculty of Public Health, Universitas \\ Airlangga, Surabaya, Indonesia
}

\begin{abstract}
Background: An annual estimate of 4 million newborns were die in the first week of life worldwide. The high rate of newborn death is showing that the health development has not accomplished (WHO, 2012). According to Health Department in (Saputri, 2013), stated that about 57\% newborn death were mainly caused by perinatal disorder and low birth weight. WHO and Unicef (2004) estimated among 20 million newborns, $15.5 \%$ baby in the world were born with low birth weight, and $95.6 \%$ among them were in developing country. The rate of low birth weight in Indonesia 2013 remained high. East Nusa Tenggara province had more low birth weight (15.6\%) than national average (10.2\%). Kupang denotes benchmark of East Nusa Tenggara province, had 337 cases of low birth weight, with the highest case came from the area of Manupaten Health Center with 35 cases (12.5\%), and the lowest came from Oepoi, 13 cases (1.1\%). One of main factors is the collaboration of health worker in integrated Ante Natal Care (ANC).

Aim: This research aimed to describe the collaboration of health worker in integrated ANC in health center.

Method: This research used qualitative method with phenomenon approach. The samples were health worker in Oepoi health center, chosen by means of purposive sampling ( 7 peoples). Result: There was a good collaboration among health workers in conducting integrated ANC in Oepoi Health Center, Kupang, involving doctor, dentist, midwife, nurse, nutritionist and laboratorian.
\end{abstract}

Conclusion: The health worker collaboration in integrated ANC has been done well.

Keywords: Health worker collaboration, low birth weight, health center

\section{Introduction}

The rate of baby death denotes one of indicator that affecting the aim of government sustainable millennium development program. Annual estimate of 4 million newborn deaths in the first week of life. The high rate of newborn death signifies that the development program in health is not accomplished yet ${ }^{(1)}$. About $57 \%$ of newborn

\section{Corresponding Author:}

Jeffrey Jap

Doctoral Student, Program of Public Health,

Faculty of Public Health, Universitas Airlangga,

Surabaya, Indonesia

Jl. Mulyorejo Surabaya, Indonesia

Email: japjeffrey@yahoo.com death occurred in less than a month old baby, and mainly caused by perinatal disorder and low birth weight ${ }^{(2)}$. A newborn considered low birth weight if the birth weight is less than 2500 gram, disregarding the gestation period. Birth weight denotes the weight of the baby an hour after the labor ${ }^{(3)}$.

Low birth weight remains a certain health problem in some countries, since it is considered as the cause of baby death. According to WHO, approximately 20million babies were born with low birth weight, and 19 million among them were from developing country, with incidence number of $11-31 \%{ }^{4}$. In developing countries, this condition is worsened by low nutrition intake during pregnancy, which causing micro-nutrients deficiency such as anemia, giving undesirable effect 
toward the expectant and the newborn ${ }^{(4)}$. WHO and UNICEF (2004) estimated about 20 million babies in worldwide, $15.5 \%$ were born with low birth weight, and $95.6 \%$ of low birth weight newborn came from the developing countries. The rate of low birth weight in developing countries were $16.5 \%$, double of developed countries, $7 \%{ }^{(5)}$.

The comparative of low birth weight cases, according to basic health survey (RISKESDAS) among provinces in Indonesia 2013, remained showing a high trend. Nationally, some provinces had a high cases of low birth weight, compared to the national average (10.2\%); namely East Nusa Tenggara (15.5\%), Middle Sulawesi (16.8\%) and Papua (15.6\%). Based on the district report 2011, it was noted that the number of low birth weight were 3484, increased in 2012 (3911), and further increased to 4457 in $2013^{(6)}$.

Kupang, denotes a benchmark for East Nusa Tenggara province, had 337 babies with low birth weight. Area of health center with the highest number of low birth weight cases was Manupaten Health Center, with 35 cases $(12.5 \%)$ and the lowest number of low birth weight cases was Oepoi Health Center, with 13 cases $(1.1 \%)$. One of main factor that correlated to low birth weight is the health service. An exquisite health service in preventing low birth weight case is necessary, especially in Ante Natal Care (ANC). Health service as the front line in giving health service, have an important role in giving health care toward society ${ }^{(7)}$.

Previous research by Sakai (2016) also stated the effectivity of inter-profession collaboration, with good attitude and assurance of the health workers. Moreover, a favorable team management capability, building a good teamwork to fulfill the goal with well-organized action, that also will motivate togive a health service with more care toward the patient. Furthermore, a good attitude and behavior can build a strong teamwork to fulfill the requirement to give a professional health service, with a better quality ${ }^{(8)}$. A good collaboration between health workers is expected to improve the quality of integrated ANC, that may prevent baby with low birth weight.

Against the foregoing situation, it is necessary to observe the collaborations between health workers in conducting integrated ANC in Oepoi Health Service in Kupang, as the health service with the least cases of low birth weight in East Nusa Tenggara. This study aimed to describe the collaboration between health workers in conducting integrated ANC in Oepoi Health Service in Kupang, East Nusa Tenggara.

\section{Material and Method}

This was a qualitative study with phenomenon approach. This study took place in Oepoi Health Center, Kupang, by means of guided interview. The examination of ANC can be evaluated from K4 report, pregnant women register and also direct observation. This study was conducted in March - June 2018, involving all the health workers in Oepoi Health Center as much as 37 peoples (4 general practitioners, 1 dentist, 9 nurses, 9 midwifes, 3 pharmacists, 2 public health scholars, 3 nutritionists, 3 sanitarians, and 3 laboratorian). After applied the inclusion criterias which were the health workers who have been working since January 2017; the health workers who are handling ANC in health center; agreed to be the respondents the samples reduced to 7 respondents.

\section{Findings}

Geographically, Oepoi belongs to the area of Oebufu District, Sub-district Oebobo, Kupang with an area of $3.5 \mathrm{~km}^{2}$. The working area of Oeipoi Health Service included 4 sub-district, namely Oebufu, Kayu Putih, Tuak Daun Merah, and Liliba. Meanwile, the human resources in each work unit in Oepoi Health Service in 2017 are 4 doctors, 1 dentist, 9 nurses, 9 midwifes, 3 pharmacists, 2 public health scholars, 3 nutritionists and 3 medical analysts.

Table 1: Health workers distribution based on age

\begin{tabular}{|c|c|c|}
\hline Age & N & Percentage (\%) \\
\hline $17-25$ y.o. & 0 & 0 \\
\hline $26-35$ y.o & 2 & 30 \\
\hline $36-45$ y.o & 5 & 70 \\
\hline Total & 7 & 100 \\
\hline
\end{tabular}

Table 1 is showing the distribution of health workers based on the age group. Most of the respondents were belong to 36-45 years old group (70\%) and the least belong to 26-35 years old group (30\%).

The evaluation of integrated ANC by the health workers of Oepoi Health Service Kupang is tabulated 
in Table 2. It was recorded that integrated ANC had been well-conducted, which mean that it was conducted according to the standard operational procedure.

Table 2: Evaluation of health workers collaboration in doing Integrated ANC

\begin{tabular}{|c|c|c|}
\hline Collaboration & $\begin{array}{c}\text { Health workers } \\
(\mathbf{N})\end{array}$ & $\begin{array}{c}\text { Percentage } \\
(\mathbf{\%})\end{array}$ \\
\hline Good $(\geq 12)$ & 7 & 100 \\
\hline Average $(6-11)$ & 0 & 0 \\
\hline Low $(<6)$ & 0 & 0 \\
\hline Total & 7 & 100 \\
\hline
\end{tabular}

Table 2 is showing that the evaluation of collaboration in integrated ANC showing that all the respondents were doing a good collaboration. The result shows that the collaboration has been done well, thus, the case of low birth weight in Oepoi Health Service is less compared to the other Health Services in Kupang.

\section{Discussion}

Collaboration between health worker in conducting integrated ANC: The description of collaboration that was done by the health workers, including doctors, dentist, midwifes, nurses, nutritionists, public health scholars and laboratorian will be explained as follows:

1. Doctors' Collaboration: General practitioners give an excellent service toward the patients, and have a good faith toward the ongoing collaboration. This can be concluded based on the doctors' statements as follows:

"I belief that all my colleagues involved in integrated ANC are able to collaborate and cooperate. All of them are giving the best according to their competence, and I belief in that. Therefore, I have no worries regarding other trivial matters."

"I give health service not restricted to pregnant women only, but also the family. I also remind them to regularly visit health center for checkup. As the head of this health center, I also acknowledge that health workers in health center have important role in preventing low birth weight."

The result of the current evaluation is in accordance to previous study by Agus (2015) which stated that a good quality of health service is necessary, particularly in preventing low birth weight, by giving ANC. Health center, as the front line in giving health services to the society have an important role, including giving ANC to the pregnant women ${ }^{(7)}$.

2. Dentists' Collaboration: Dentist is also reported giving a good health service. There are two dominant aspects that correspond to the general practitioner did, namely have faith in collaboration and give a full care of treatment to the patients. These are the dentist's statement:

"It's an honor to be able to cooperate with other profession."

"We always discuss all the things that we don't understand"

"Our duty is to communicate to other team members, so that we can work together, caring the pregnant women. We do our best to prevent oral and dental problems in pregnant women, and immediately treat those who have oral and dental problems."

Those statements is correspond to the theory of collaboration, which stated that a collaboration is based on principles of togetherness, equality, responsibility and accountability ${ }^{(9)}$.

3. Midwifes' Collaboration: Midwifes also have contributions in this collaboration. The result of observation also proved that midwifes gave services better than the others. Their statements as follows:

"This is a sacred profession, and of course, I belief that inter-profession teamwork may make better integrated ANC, thus, preventing low birth weight."

"We cannot work all alone, there are team from the other profession that give us so much help. Without them, I don't think we can make it happen."

This result is in accordance to the statement that a goal can be accomplished faster and better if done in teamwork. In a good teamwork, the team member should be able to cooperate and collaborate to reach the set goal ${ }^{(10)}$.

4. Nurse Collaboration: The observation revealed that the nurses in health center were able to build 
a good collaboration. A good attitude and belief as a professional, is an important factor to build a good teamwork. These are the nurses' statements:

"I have faith in our colleagues, that they are able to complete the task well."

"In every meeting, I always give my best to keep this team solid."

According to Smith (2017), collaboration is a process where the doctors, nurses, and other health workers create a plan and work together as colleagues, with each other competencies limitation and give respect to each other involved in giving services toward individual, family, and society ${ }^{(11)}$.

5. Nutritionists' Collaboration: Nutritionists in health service also doing a good collaboration, by giving deep care toward the patient and also the team, which help make the team become solid. These are the statements of the nutritionists:

"I give support and my best to our colleagues in other profession. When there is pregnant women with nutrition deficiency, I will give food supplement, health education and regular nutrition counseling immediately, until they recovered."

"We will also educate the family, so that they can help pregnant women in home."

To build a good collaboration, giving each other support is necessary. Each profession occasionally doing their work separately, this may be an obstacle in collaboration. The willing to share, depend and help each other will eventually improve the collaboration ${ }^{(11)}$.

6. Public Health Scholars' Collaboration: Public health scholars also did a good job in collaboration, better than the other profession. Public health workers have a good team management, which may encourage the society in health service work area to build a collaboration to prevent any pregnancy disorder, and especially, prevent baby birth with low birth weight. These are the statements of public health workers:

"Aside from this team, we also try to reach ward office to work together in facing public health problem, especially regarding pregnant women."
"Actually, the key role lays in communication among team member. The more we have intense group discussion and good communication, the less weight we bring, as all of the team member are there to give a hand."

In collaboration, a good communication is necessary to make the work and message relay ease. Each member should be able to receive and give advices to others. Communication is a key in a collaboration ${ }^{(12)}$.

7. Laboratorian Collaboration: Laboratorian did a good job in collaboration, by giving a better service and care toward the patient. This may be due to their focus more on laboratory.

"Our duties, indeed, in laboratory. All the pregnant women who did check-up will get a good service, and we also discuss with our other-profession colleagues."

"We convey and discuss the lab test result of the pregnant women, so that we can give the best explanation and advice to prevent painful labor and baby with low birth weight."

The knowledge from each individual, should be shared to help the others. Therefore, it may help to find a better solution to face a problem together ${ }^{(12)}$.

\section{Conclusions}

Based on the observation, it can be concluded that integrated ANC by the health workers in Oepoi Health Center is well-conducted with a good coordination, which make the low number of low birth weight cases in Oepoi Health Center. In order to maintain the good achievement, it is advised to distribute the necessary tools of ANC to the health workers in health center. This collaboration model can be adopted by other health service, although a further research remains

Conflict of Interest: There is no conflict of interest for every author.

Source of Funding: This research funded by self-funded

Ethical Clearance: There are no human participants involved in this research. However the procedure of this research had already gotten ethical approval of Health Research Ethics Committee, Faculty of Public Health, Univeritas Airlangga. 
Informed Consent: Informed consent was obtained from all individual participants included in the study.

\section{REFERENCES}

1. WHO. Annual report 2012. Geneva: Centre for Health Development (WHO Kobe Centre); 2012. $3-14$ p.

2. Saputri I. Pengukuran Kinerja Internal dan Eksternal pada Puskesmas Manukan Kulon Surabaya. Universitas Airlangga; 2013.

3. Hidayatush S, Sri SM. Analisis Risiko Kejadian Berat Bayi Lahir Rendah (BBLR) Pada Primigravida. Media Gizi Indones. 2015;10(1):57-65.

4. Mochamad SP, Astridya P. Pattern of Occurrence and Determinants of Baby with low birth weight in Indonesia. Bul Penelit Sist Kesehat. 2015;18(1):1-10.

5. WHO. Optimal feeding of low birth weight infants. Geneva: WHO; 2006. 8-9 p.

6. Dinas Kesehatan Prov. NTT. Profil Kesehatan Provinsi Nusa Tenggara Timur Tahun 2015. Kupang, NTT: Dinas Kesehatan Prov. NTT; 2016. $101 \mathrm{p}$.

7. Muhammad AM, Tety R. Policy Analysis of Integrated Antenatal Care implementation at Public Health Centers in Blitar City. Bul Penelit Sist Kesehat. 2016;19(1):41-53.
8. Ikuko S, Takeshi Y, Yoshinori T, Takashi M, Yuuko K, Kana K. Development of a new measurement scale for interprofessional collaborative competency: The Chiba Interprofessional Competency Scale (CICS29). J Interprof Care. 2017;31(1):59-65.

9. Roberts JM, Redman CWG. Global Pregnancy Collaboration: Overview and recommendations. In: Global Pregnancy Collaboration symposium: Prepregnancy and very early pregnancy antecedents of adverse pregnancy outcomes. Placenta; 2017. p. 103-9.

10. Deborah LD, Gylo H, Lynette MJ. Promoting Interprofessional Collaboration: A Pilot Project Using Simulation in the Virtual World of Second Life. J Res Interprof Pract Educ. 2017;6(2):1-15.

11. Smith HA, Reade M, Maar M, Jeeves N. Developing a grounded theory for interprofessional collaboration acquisition using facilitator and actor perspectives in simulated wilderness medical emergencies. Rural Remote Heal. 2017;17(1):3880.

12. Brenda JS, Heather KSL. Development and testing of a conceptual framework for interprofessional collaborative practice. Heal Interprofessional Pract. 2014;2(2):1066. 